\title{
Corrigendum
}

\section{Corrigendum to "Pus in Spinal Needle: Diagnosis and Management of a Long-Segment Spinal Epidural Abscess"}

\author{
B. M. Munasinghe $\left(\mathbb{D},{ }^{1}\right.$ N. Pathirage $\mathbb{D D}^{1}{ }^{1}$ M. S. Hameed $\mathbb{D}^{2},{ }^{2}$ and C. T. Hapuarachchi ${ }^{3}$ \\ ${ }^{1}$ Department of Anaesthesia and Intensive Care, District General Hospital, Mannar, Sri Lanka \\ ${ }^{2}$ Consultant Orthopaedic Surgeon, District General Hospital, Mannar, Sri Lanka \\ ${ }^{3}$ Department of Microbiology, District General Hospital, Mannar, Sri Lanka
}

Correspondence should be addressed to B. M. Munasinghe; malakafmp@gmail.com

Received 5 August 2021; Accepted 5 August 2021; Published 14 August 2021

Copyright (c) 2021 B. M. Munasinghe et al. This is an open access article distributed under the Creative Commons Attribution License, which permits unrestricted use, distribution, and reproduction in any medium, provided the original work is properly cited.

In the article titled "Pus in Spinal Needle: Diagnosis and Management of a Long-Segment Spinal Epidural Abscess" [1], the authors identified an error in the Introduction section. Following the publication of the article, the authors identified a previously published similar case of a patient with an epidural abscess suspected during spinal anaesthesia. The article should therefore be corrected as follows, with the addition of reference 12 [2]:

"Interestingly, SEA presenting itself during subarachnoid anaesthesia has never been reported to the best of our knowledge." should be corrected to "Interestingly, SEA presenting itself during subarachnoid anaesthesia has very rarely been reported in literature [12]."

\section{References}

[1] B. M. Munasinghe, N. Pathirage, M. S. Hameed, and C. T. Hapuarachchi, "Pus in Spinal Needle: Diagnosis and Management of a Long-Segment Spinal Epidural Abscess," Case Reports in Infectious Diseases, vol. 2021, Article ID 9989847, 4 pages, 2021.

[2] D. Sahu, R. Parampill, and V. Kaul, “"Dry tap” during spinal anaesthesia turns out to be epidural abscess," Indian Journal of Anaesthesia, vol. 56, no. 3, pp. 287-290, 2012. 